\title{
Investigation of the Interaction of Students' Mental Models with Peer Instructional Elements in an Undergraduate Physics Course
}

\author{
Nilüfer Didiş Körhasan* \\ Faculty of Education, Department of Mathematics and Science Education, Physics Education Major, Zonguldak Bülent Ecevit University, Turkey \\ *Corresponding Author: niluferdidis@gmail.com
}

\section{ABSTRACT}

Peer instruction (PI) involves interaction between students and provides opportunities for students to reveal their own ideas, articulate their thinking, and facilitate construction of their knowledge with social interaction. Since the classroom environment of PI provides a rich information for students to discuss scientific phenomena, this research examined how students' mental models interacted with Peer Instructional elements in an undergraduate level physics course. After the identification of students' mental models of wave-particle duality in the first step of the project, the analyses of several data sources showed that some group-related issues, such as the explanatory based annotations before classes, good performance answering conceptual questions, and discussion of additional concepts during classes, were important for scientific understanding. When students have similar group environments (i.e. peers in the same group), then individual pre-class preparation had a positive influence on students' scientific mental models of wave-particle duality. In addition, students having scientific models indicated that the satisfaction with their knowledge and the importance of conflict with their peers for their learning. All students in the classroom stated they benefited from peer discussions in different ways such as by recalling and reinforcing their knowledge, by getting feedback, and by reconstructing their knowledge. Both pre-class preparation and discussion of additional concepts and conflicting ideas in peer groups should be promoted in physics classes for facilitation of construction of scientific mental models.

KEY WORDS: science education; physics education; mental models; peer instruction; wave-particle duality

\section{INTRODUCTION}

T he pedagogy used in the classroom has a large impact on how students organize new information into mental models, which develop through interactions in a social environment (Didiş Körhasan et al., 2016). It is therefore important for classrooms to provide a social environment with opportunity for human communication and interactions (Johnson-Laird, 2004; Vygotsky, 1978).

When new information is abstract, counter-intuitive, and mathematical as is the case with quantum theory, it is even more important that classrooms provide social environments for students as they construct their mental models. Research has shown the importance of student interaction on the development of their mental models. Didiş Körhasan et al. (2016) investigated peer-instruction interactions in a lecturebased teaching environment and found these interactions to be critical to the development of students' mental models about the quantization phenomenon in an undergraduate level modern physics course.

Peer instruction (PI), which is an instructional methodology based on the social constructivist theory of learning, increases student interaction in crowded physics classrooms in lecture halls (Mazur, 1997). PI provides opportunities for students to reveal their own ideas and articulate their thinking as they discuss concepts with each other (Mazur, 1997). Using the social constructivist theory of learning and the mental models theory from cognitive science, this mixed methods study conducted in an undergraduate level physics course at Harvard University examined the interaction of students' mental models of a quantum mechanical concept "wave-particle duality" with PI elements (i.e. methodological issues and peers) in a PI environment.

$\mathrm{Pl}$

PI is centered around students persuading one another, through discussion, of the correct answer to a posed question. Questions posed during PI (called "ConcepTests") focus on basic concepts and are designed, by the instructor, to elucidate the misconceptions commonly held by students (Mazur, 1997). With the presentation of ConcepTests integrated into lectures, students are kept mentally active and motivated (Crouch and Mazur, 2001). With the focus on conceptual understanding, lectures are mainly used for discussing and deepening students' understanding (Mazur, 1997). PI facilitates the construction of students' knowledge through social interaction.

The use of PI does not rely on financial and technological resources (Mazur, 1997). However, for PI to be effective, there are some methodological guidelines that must be followed by 
instructors. For example, students should read the material before class. Instructors should collect feedback from students on which topics from the reading were most confusing to decide which concepts to emphasize in class. In class, the instructor should briefly present these concepts, and then ask students a ConcepTest. Students answer each ConcepTest individually in the first-round. If the initial percentage of correct answer is lower than 30\%, this suggests there are not enough students for effective peer discussion and, the instructor should revisit the concept before engaging students in peer discussion. If between $30 \%$ and $70 \%$ (sometimes reaching up to $90 \%$ according to topic) of students answer the ConcepTest correctly, the instructor asks students to discuss the question with their peers and answer again in the second-round. If the correct percentage is larger than $70 \%$, the correct answer is explained by the instructor (Mazur, 1997).

Peer discussion has been shown to be the most important part of the PI methodology (Vickrey et al., 2015). Mazur (1997) showed that students are more effective than their instructors at explaining concepts to one another. As they are all novices, students are more familiar with common conceptual difficulties than their instructors whose level of expertise can obscure these difficulties (Singh, 2005). Peer discussion keeps students active and reduces their cognitive load in class (Singh, 2005). It has also been shown that students' qualitative problem-solving abilities are improved through peer discussions (Giuliodori et al., 2006). Peer discussions have been shown to increase students' understanding even when no one knows the correct answer (Smith et al., 2009) as students activate each other's appropriate cognitive resources (Wood et al., 2014).

The use of PI creates an active, social learning environment that makes teaching and learning easier in crowded classrooms (Mazur, 1997). For this reason, PI is a widely used pedagogy (Fagen et al., 2002) not only at universities but also in other educational settings. Research has shown that PI is very effective in improving students' physics problem solving skills, conceptual understanding, attitudes, and self-efficacy beliefs (Crouch and Mazur, 2001; Gök, 2012; 2015; Lasry et al., 2008; Miller et al., 2014; 2015). In addition, Lorenzo et al. (2006) found that PI effectively reduces the gender gap in physics classes. In classes taught with PI, female students improved more than the male students. The survey results of Fagen et al. (2002) indicated that learning gains obtained using PI are comparable with those obtained with other interactive engagement pedagogies. In addition, $80 \%$ of the instructors who used PI found it to be successful, and $90 \%$ stated they would continue to use it.

In the light of the cognitive and affective benefits of PI in literature, this study focused on how PI contributed to the construction of mental models with a socio-cognitive perspective. Mental models are coherent knowledge organizations of individuals in their minds and learning occurs with the active construction of mental models (Didiş et al., 2014). Some factors such as previous knowledge and experiences, how the new information presented during teaching, language, interaction with the system, teacher, and peers influence the construction of mental models (Collins and Gentner, 1987; Didiş Körhasan et al., 2016; Norman, 1983; van der Veer et al., 1999). With the characteristics of peer discussions keeping students mentally active (Crouch and Mazur, 2001), reducing cognitive load (Singh, 2005), coordinating and deepening understanding (Jeong and Chi, 2007; Mazur, 1997), activating cognitive resources (Wood et al., 2014), and PI provides a social environment to students for the construction and revision of knowledge through mental models. Some of the studies in literature on mental models of students focused on the quantum mechanical concepts (Ayene et al., 2019; Didiş et al., 2014; Didiş Körhasan and Wang, 2016; Ke et al., 2005; Park and Light, 2009; Stefani and Tsaparlis, 2009). However, these existing studies investigate students' mental models of quantum theory in lecture-based teaching environments which provide students with limited opportunity to construct their mental models through discussion. PI provides a rich opportunity for students to discuss quantum phenomena, which has highly unfamiliar content different from the classical physics, and how students construct their mental models of quantum physics in a social environment is worth examination. With this aim, after the identification of students' mental models of wave-particle duality in the first part of the project (Didiş Körhasan and Miller, 2020), this study focused on the interaction of mental models with PI elements, which were the "methodological issues" and "peers" in a PI environment.

\section{METHODOLOGY}

Development of mental models in a social environment is reflected in this research with the analyses of several data sources. Figure 1 shows the timeline for the data collection and the data analysis of this research conducted in 2016.

As shown in Figure 1, for investigation of students' mental models with the methodological issues and peers in a PI environment, different types of data consisting and reflecting the elements of PI were collected during the research: (1) Students' annotations of all the pre-class reading assignments that pertained to the quantum mechanics topics were collected and analyzed; (2) all student responses to the ConcepTests asked during classes pertaining to wave-particle duality topics were also collected; (3) in addition, interviews with a sub-set of six students registered in the class were conducted; and lastly, (4) a questionnaire, and (5) peer checklists were administered to all the students registered in the course.

After the analyses of these data sources, mental models of waveparticle duality identified in the first part of the project (Didiş Körhasan and Miller, 2020) were taken into consideration. To understand the interaction of mental models with the methodological issues and peers in a PI environment, identified mental models were interpreted together with the findings from several data sources of this mixed methods research. 


\section{Data Collection}

In this research, ethical issues such as informing the participants and getting their consents, assurance of keeping participants away from any physical, psychological and physiological harm, and the privacy of data (Fraenkel and Wallen, 2000) were considered and the permission was obtained from the Institutional Review Board (IRB) of Harvard University.

\section{Description of the research setting: Applied physics course}

This study was conducted in Applied Physics 50B in the School of Engineering and Applied Science at Harvard University. It is an introductory calculus-based physics course intended for engineering and premedical students. It is an interactive, team and project-based course and relies heavily on peer interaction and discussion. Online pre-class reading assignments and in-class PI sessions during which the instructor focuses on questions that students have indicated, during the pre-class reading, as being unclear were fundamental for this course. Students were required to complete a pre-class reading assignment via an online, social annotation platform before each class. It is a semester-long course (approximately 13 weeks) covers introductory topics in electricity, magnetism, optics, and modern physics. For this research, the portion devoted to quantum mechanics which was the past 4 weeks of the course was the focus.

\section{Participants and peer groups}

In the implementation of PI, all in-class activities, assessments, and projects were done in teams that were formed by the instructor. Students work closely with three or four peers throughout the course. There were 15 groups dependent on the number of students taking the course $(n=60)$. The data for questionnaire, peer checklist, reading annotations, and questionnaire were collected from all members of these groups in the class; however, selection of students representing the groups was considered for the interviews. For the interviews, five of the 15 peer groups were studied and six students ( 5 females, 1 male), two of whom were in the same group, were selected by purposive sampling with good, average, and weak class performances.

\section{Reading annotations}

Students' reading of the concepts in the textbook before the classes is important for the effectiveness of PI. It provides students with the relevant content to use during the discussion phase of PI. An online social annotation system was used (Miller et al., 2016) for pre-class preparation of students. Students logged-on and completed the reading online while highlighting and annotating the text within the social environment the platform provides. Students asked questions about specific areas of confusion within the reading and these questions could be addressed online by other students and, the following day, by the instructor in class - during the PI sessions. Students' annotations were one of the types of data collected in this research.

\section{ConcepTests}

ConcepTests are short, usually multiple choice, conceptual questions that focus on specific concepts. They are administered during class to provide ongoing assessment of students' learning. They probe and deepen students' understanding of the course content.

A web-based electronic response system was used to pose the conceptual questions during PI. This system allows for PI to be implemented via the integration of technology more sophisticated than clickers and is an effective way for gathering students' responses to questions. The system enables the instructor to ask many different types of questions (open ended, numerical, and sketching) beyond multiple choice (which is the only type of question instructors can ask using clickers). ConcepTests were also used as one of the data sources or this research.

\section{Interviews}

To identify the interaction of mental models with the methodological issues of PI and peers, six out of the 60 students in the class were interviewed. The interview questions were examined by an expert to check for content validity. In the interviews, students related their experience with their peers in PI environment with their construction of knowledge on wave-particle duality. They also discussed how their peers in their own groups influenced their understanding the concepts. All interviews were video recorded and the interviews took approximately $20 \mathrm{~min}$ for each student.

\section{Questionnaire}

How much a student knows is an important variable in shaping the nature of a discussion in a social environment. Given this, the questionnaire focused on understanding how students organize their knowledge when they are at different knowledge

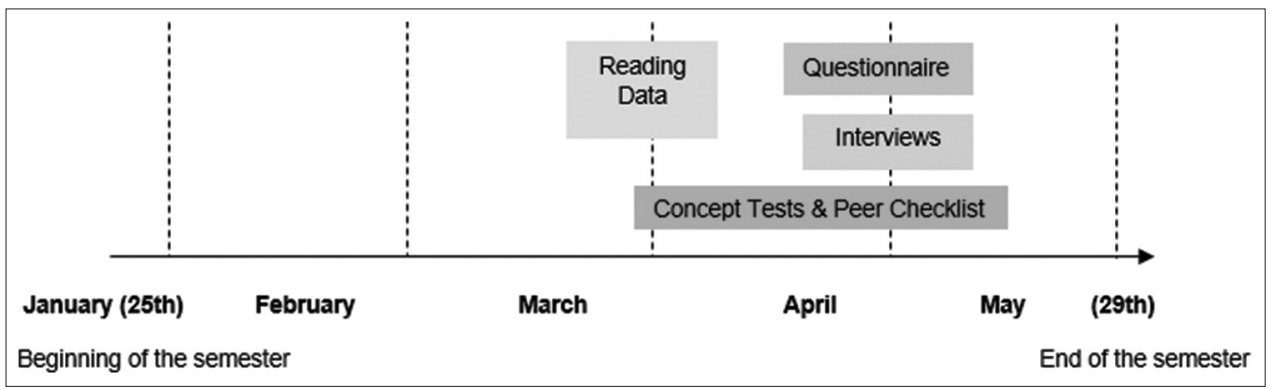

Figure 1: Timeline for the data collection and the data analysis of the research 
levels from their peers (i.e. more knowledge than their peers, less knowledge than their peers, and the same knowledge as their peers). The questionnaire included questions investigating both situations when the students had similar and conflicting ideas.

The questionnaire examining students' approach to organizing their knowledge in different kinds of social environments was examined by the same expert to check for content validity. After feedback from the expert was received, some questions were eliminated. The final version of the questionnaire used in this study had 14 questions.

\section{Peer checklist}

A peer checklist was designed to understand what was going on during peer discussion when students were answering ConcepTests during class. In the development of Peer Checklist, the literature (Hewson, 1981; 1984; Posner et al., 1982) about knowledge organization (by addition or revision) was taken into consideration. Students were asked to select up to three statements which described the interactions with their peers during peer discussions (Appendix).

\section{Identified mental models}

In the first part of the project, four different kinds of mental models of wave-particle duality were identified (Didiş Körhasan and Miller, 2020). "Photoelectric effect" and "Double-slit experiment with an electron beam" quantum contexts were used for the examination of particle nature of light and wave nature of matter, respectively. The identified mental models of students from advanced to primitive were as follows: Quantum Model (QM), Hybrid model (HM), wave model (WM), and in-between model (IM).

1. QM is the scientific mental model of wave-particle duality. Students displaying this model have clear and coherent ideas of classical and quantum perspectives. In this model, with the explanation of particle nature of light and wave nature of matter, students could explain the "duality" for both light and electron

2. HM can be considered as a transition from a classical to a quantum model because students having this model explain the "duality" for one of the elements (light or matter), but not for the other. Because it indicates lacking the correct connection of concepts to be considered a full representation of quantum mechanical ideas, it is an unscientific model

3. $\mathrm{WM}$ is an unscientific model that a single wave nature was considered for both light and matter

4. IM represents a new and unscientific type of understanding for the "duality." This model involves combining their wave and particle characteristics instead of them having a dual nature.

\section{Data Analysis}

The analyses of five types of data sources were conducted to investigate the interaction of mental models with PI elements such as the methodological issues and peers.

\section{Reading annotations}

All student annotations of the online reading assignments that pertained to quantum mechanics were compiled and a content analysis was conducted to this data. In the analysis, it focused on what kind of annotations was made by students. The annotations were categorized as explanation type (E), question type (Q), and both explanation and question (EQ) type. While some of the students were making annotations as E, Q, or EQ type, some of them never asked questions and made explanations about the topics when reading the material. In this research, the annotations about wave-particle duality related concepts made by the six students and their peer groups were examined. Based on this categorization of annotations, each peer group's pre-class preparation was coded as "explanatory based (E)" with mostly explanatory annotations or as "heterogeneous (E, Q, EQ)" with a mix of different type of annotations.

\section{Concept tests}

Students' individual (round 1) answers to the ConcepTests and their responses to the ConcepTests on quantum mechanics topics after the peer discussion (round 2) were analyzed. The cases where students switched their answer between the two rounds were identified. Based on the percent of correct answers in round 2, each group was categorized as high performers, moderate performers, or low performers. If a peer group answered most of the ConcepTests in round 2 correctly, this group was coded as "high performers," if they answered almost half of the questions correctly, this group was coded as "moderate performers," and if they answered most of the questions wrong, this group was coded as "low performers." Due to their answers, different inclass performances for groups were identified.

\section{Interviews}

The transcribed interviews were analyzed by considering students' explanation about the characteristics of peers, knowledge organization with peers, content, and effectiveness of peer discussion. As well as the analyses of interviews provided qualitative information about students' personal ideas about peers and knowledge organization, they also were important for the determination of the nature of the peer discussion environment. For example, in the analyses, the groups discussing only how matter and light behaved in a taught context and not discussing other else when answering the questions were called as "context-limited." The groups discussing the nature of matter and light for other contexts fully understanding of wave-particle duality were called as "context-plus."

\section{Questionnaire}

The analysis of the questionnaire focusing on the knowledge construction was important for understanding of students' knowledge construction approach based on peers' knowledge. In the analysis, six interviewed students' choices presenting their approach to knowledge construction when their peers had different level of knowledge (i.e. more knowledgeable or less knowledgeable) were determined. 


\section{Peer checklist}

Descriptive analysis was conducted to peer checklist data given by the web-based electronic response system. With peer checklist, students reflected about their knowledge organizations when they were answering the in-class questions. By this way, different natures of peer discussion were identified such as construction new knowledge by combining peers' knowledge together, or by revising their different opinions, or discussion of already known.

\section{RESULTS}

In this research, the analyses of the several data sources were interpreted together with identified mental models in the first part of the project (Didiş Körhasan and Miller, 2020). The following results indicate the interaction of mental models with the methodological issues and peers in a PI environment in an undergraduate level physics course.

\section{Interaction of Mental Models with the Methodological Issues of PI}

This part discusses how students' mental models interacted with the methodological issues of PI in three parts: (1) Pre-class preparation of students with reading annotations, (2) in-class performances in answering the ConcepTests, and (3) post-class reflections about peer discussion.

With the analyses of pre-class preparation (students' annotations such as questions or explanations on the reading material), peer groups' preclass performances were determined and Table 1 was constructed.

Table 1 presents the pre-class preparation of each of six participants (from St1 to St6) and their peers in their groups before the teaching of wave-particle duality with PI. It shows that different peer groups had varying amounts of pre-class preparation. For example, while all students in Group 2 annotated the reading about wave-particle duality either as a question (Q) or an explanation (E) or both explanation and question (EQ), only one student (St4) from Group 1 annotated. By considering the explanation-like or questionlike annotations on the reading material, Groups 1,3 , and 4 can be categorized as explanatory based because their annotations were mostly E and EQ types; and Groups 2 and 5 can be considered as heterogeneous due to the nature of their annotations including E, Q, and EQ types.

In-class findings were based on performances in answering ConcepTests recorded by the web-based electronic system.
The analysis of performances of peer groups during the teaching of wave-particle duality indicated that the groups had different level of performances due to the given correct answers in the second round. The students in Group 1 almost explained all in-class questions (conceptual and reasoning with mathematical calculations) with peer discussion correctly during the teaching of wave-particle duality with PI. They had good peer collaboration getting the correct answer in the second round. The Groups 3 and 4 were similar, and they answered almost half of the in-class questions correctly with peer discussion; however, the Groups 2 and 5 answered less than half of the in-class questions correctly. In conclusion, peer group performances were high (for Group 1), moderate (for Groups 3 and 4), and low (for Groups 2 and 5) during teaching.

In the post class reflections, six participants explained to what extent they discussed the nature of matter and light with their peers when they were answering the questions asked by the instructor during PI. Groups 1 and 3's discussions included the nature of matter and light for other contexts and so the discussions of these groups were classified as "context-plus." Students in Groups 2, 4, and 5 explained they had discussed only how matter and light behaved in a taught context and did not discuss other contexts when answering the questions. Therefore, the discussions of these groups were classified as "context-limited."

With the combination findings about students' mental models and findings from three data sources obtaining preclass (annotations), in-class (ConcepTests), and post-class (Interviews), Table 2 was constructed.

Table 2 is composed of student-based and group-based results obtained with the analyses of different data sources to be able to interpret the interaction of mental models with PI elements. According to Table 2, St3 and St4 had the scientific model, which was QM. When groups of these students were examined, Groups 1 and 3 presented high and moderate peer discussions based on the pre- and in-class activities, respectively. In addition, these groups provided explanatory based pre-class preparation and context-plus discussions. The most prominent difference between these groups and Group 4 was based context-limited discussions when answering the questions. St5 in Group 4 displayed unscientific IM which is a new kind of explanation considering wave and particle nature at the same time. Other students in the group with context-limited peer discussions (Groups 2 and 5) presented also unscientific

\begin{tabular}{|c|c|c|c|c|c|}
\hline Group Members & Group 1 & Group 2 & Group 3 & Group 4 & Group 5 \\
\hline 1 & St1: - & $S t 2: \mathrm{Q}, \mathrm{Q}$ & St3: E, E, E & St5: - & St6: - \\
\hline 2 & St4: EQ, EQ & Peer2: Q, E, Q & Peer2: Q & Peer2: - & Peer2: E \\
\hline 3 & Peer3: - & Peer3: E & Peer3: - & Peer3: EQ & Peer3: Q, EQ, \\
\hline 4 & & Peer4: EQ, E, Q & & Peer4: E, E & Peer4: EQ, EQ \\
\hline
\end{tabular}




\begin{tabular}{|c|c|c|c|c|c|c|c|}
\hline \multicolumn{2}{|c|}{ Peer groups } & \multicolumn{3}{|c|}{ Student-based analysis } & \multicolumn{3}{|l|}{ Group-based analysis } \\
\hline $\begin{array}{l}\text { Peer } \\
\text { group } \\
\text { No }\end{array}$ & $\begin{array}{l}\text { \# of } \\
\text { students in } \\
\text { each group }\end{array}$ & Students & $\begin{array}{l}\text { Mental models } \\
\text { of wave-particle } \\
\text { duality }\end{array}$ & $\begin{array}{l}\text { Pre-class preparation } \\
\text { (reading Annotations) }\end{array}$ & $\begin{array}{l}\text { Pre-class preparation } \\
\text { (reading Annotations) }\end{array}$ & $\begin{array}{l}\text { In-class work } \\
\text { (ConcepTests) }\end{array}$ & $\begin{array}{l}\text { Post-class reflections } \\
\text { about peer discussion } \\
\text { (interview) }\end{array}$ \\
\hline \multirow[t]{2}{*}{ G1 } & 3 & St1 & $\mathrm{HM}$ & - & Explanatory based & High & Context-plus \\
\hline & & St4 & QM & EQ & & & \\
\hline G2 & 4 & St2 & WM & Q & Heterogeneous & Low & Context-limited \\
\hline G3 & 3 & St3 & QM & $\mathrm{E}$ & Explanatory based & Moderate & Context-plus \\
\hline G4 & 4 & St5 & IM & - & Explanatory based & Moderate & Context-limited \\
\hline G5 & 4 & St6 & $\mathrm{HM}$ & - & Heterogeneous & Low & Context-limited \\
\hline
\end{tabular}

models. This case indicates the importance of the discussion of other physical phenomena in peer discussion and not limiting the discussion with only the taught context.

The students (St1 and St4) in the same group (Group 1) were also examined. Although they had the same social environment for learning with peer discussion, they displayed different models such as HM and QM, respectively. As the student-based analysis presented, while St4 made explanation and question type annotations during pre-class preparation, St1 did not display either question-like or explanation-like annotations before class. This case indicates that pre-class preparation may have a role on students' construction of scientific models when they have the similar social environments for learning.

In addition, the other students who did not make any explanation-like or question-like annotation presented unscientific mental models. This also indicates the importance of pre-class preparation in the construction of scientific mental models in a PI environment.

\section{Interaction of Mental Models with Peers}

In this part, interaction of students' mental models with peers was examined in three parts: (1) in terms of the characteristics of peers, (2) in terms of knowledge organization with peers, and (3) benefit from peer discussion with the different effects of peers.

In the analyses of interviews, two important variables were identified in students' explanations about the characteristics of peers influencing their learning during peer discussions. One variable is the "physics thinking/knowledge of a peer," and the other one is "respect of a peer." These two variables are interrelated with each other and with students' knowledge construction. An excerpt from student four's explanation follows:

St4: I think a group that has everybody has around equal comfort and discomfort with the material. Sometimes in your group with a person who is really good at physics who knows everything in the class. They can dominate the discussion and just can be like "this is right, this is wrong" and you don't really have any sort of discussion about topic. I don't think this is very effective. I think in order to have effective discussion it is important that nobody feels intimidated, nobody feels like stupid. There must be nobody dominating the discussion. I think people must be receptive the other ideas and ok with questioning other people's beliefs, and also respectful of other people's opinions...

St4 was a student having the scientific model QM. Another student St2, having the unscientific model with missing scientific ideas, also gave a similar explanation:

I: Which elements about your peer/peers influence your knowledge construction when you are discussing on the topics?

St2: I think the hardest thing have a group there is someone who really core understanding of physics because you got a tough problem that if only one or two people ever really know what is going on in the group. If you have a really tough question and one or two people can answer and you have a group member who don't care that much, you don't have a good understanding of physics then it is hard to answer that question. You don't need to be really good at physics, you just need to be ok, and you just have to know something... The ability to understand what is going on physics.

The students indicated physics knowledge/ability might drive the social behavior such as being respectful, kind, or the opposite such as being dominating. It was explained that they were critical for learning. Some similar excerpts from the other students are presented below:

St3: I think it is more important that people coming already read things and having ideas. I think it is more important, maybe to be curious. Because otherwise there won't be a discussion or you won't think about things together. I think most important characteristic to be willing to say thoughts. It is better if like everyone feels comfortable talking even if they are not completely sure about the material... It is also nice to have people with different ways of thinking about the problem, maybe one person thinks more quantitatively, one person thinks qualitatively. It is important to establish the concepts in your head better.

St1: It is really helps just having someone has been focused and dedicated reading. For my knowledge 
construction, I like to have equations to look at which reflect the concepts...

\section{I: What about social elements?}

St1: Yeah. Someone who respects opinions... Generally kind people.

St6: It helped me figure out what I was missing, what I did not understand.

I: For your understanding, what kinds of groups are very productive for your learning? You can maybe explain such kind of social issues important in your learning.

St6: When I was in the groups that care a lot about the subject, we did better. With people that were understanding and tried to be patient with each other. We all learn more really depended on how much people care.

All six students indicated the importance of being respectful during peer discussion. Being respectful does not provide conceptually correct explanations during peer discussion; however, it may direct group discussion dynamics and affect the other students' performances and gain during discussion. The explanations given in the interviews indicated that physics knowledge/ability of peers was an important variable in students' learning in a PI classroom.

To interpret how students approached organize their knowledge when working with their peers, students' comparison of their own knowledge with their peers' knowledge was determined by interviews. This was a kind of metacognitive evaluation and a reflection about the knowledge of peers in the group. Then, the questions in the questionnaire focused on students' approaches toward knowledge construction when they compared their knowledge with their peers' knowledge. By this way, students' approaches such as "directly accepting the ideas of peers during peer discussion", "revision of knowledge structure and construction," and "being resistant to knowledge construction during peer discussion" in different conditions (with similar or conflicting ideas) were determined due to having peers with different knowledge levels. As a result, each of six student's answer in the questionnaire based on comparison of own and peer's knowledge was determined. Finally, by peer checklist, three different natures of peer discussion were identified with students' self-evaluations such as (1) construction new knowledge by combining peers' knowledge together, (2) by revising their different opinions, or (3) discussion of already known. Similar to the previous sections, by the combination of the results of the analyses of different data sources such as interview, questionnaire and peer checklist, Table 3 was constructed to examine the role of peers on knowledge construction and it reflects how students' mental models varied by considering the issues emerging from peers.

Table 3 indicated four of the six (St1, St2, St3, and S4) participants explained "knowledge construction" in their peer discussion during the teaching of wave-particle duality, two of them ( $\mathrm{St} 5$ and St6) stated that they discussed on what they had already known to answer the in-class questions. These two students held unscientific and classical ideas about the wave-particle duality, respectively.
When the mental models of the four students were examined, St3 and St 4 had scientific models. When the answers of these students in the questionnaire examined, they presented they asked questions and try to construct new knowledge. In the interview, one of these students (St3) mentioned that her knowledge was more than her peers, and St 4 mentioned that he had well knowledge as his peers. By considering these metacognitive evaluations and tendency to knowledge organization of students, satisfaction or confidence about knowledge of wave-particle duality might have a role on their scientific mental models. More clearly, St3 with QM was more satisfied with their physics knowledge when compared to their group peers; however, the others presented unscientific models reported to feel that they had limited physics knowledge by comparison to their peers.

In addition to these six students, Figure 2 presents how other students answering the questionnaire (51) in the class approached to knowledge construction in the PI classes.

Figure 2 presented that students mostly thought that they were curious to revise and reconstruct their knowledge with peer discussion with the selection of choice B with a great percentage. This is important that indicating students did not aim just to answer the questions when they are working with their peers, they also tried to organize their knowledge and try to benefit peer discussion.

Finally, students' benefit from PI examined with $14^{\text {th }}$ question in the questionnaire. Students were requested to consider "getting feedback from their peers about their knowledge and improving their knowledge," "their peers' reminding them of their knowledge and reinforcing their knowledge," "having confliction between their peers' knowledge and their knowledge and reconstructing my knowledge," and "no effect." All of six participants explained the effectiveness of peer discussion for their construction of own mental models of the wave particle duality in different ways. For example, the students having scientific model QM (St3 and St4) indicated the choice " $\mathrm{C}$ " which is "Having confliction between peers" knowledge and my knowledge and reconstructing my knowledge," the students with unscientific models indicated the choice A(St2, St5, and St6), which is "Getting feedback from my peers about my knowledge and improving my knowledge" and the choice "B" (St1), which is "Recalling of my knowledge by my peers and reinforcing my knowledge." St2 reflected how she benefited from peer discussion in interview:

St2: During classes, there is always lots of discussion and you are rarely sure. It was very helpful to have a group to be able to see who answered what question. Three or five people answer the question in the same way... Sometimes no one got the right answer but you think, combine and create in consensus. I think the groups are super helpful in most of the time, when you got stuck about the group that's not helpful.... I have positive outlook about the group dynamics.

Interview findings also revealed that students with scientific models indicated the importance of confliction for reconstruction of knowledge. The following excerpt belongs to St4 with scientific model QM: 
Science Education International

32(3), 220-230

https://doi.org/10.33828/sei.v32.i3.5

Körhasan: Interaction of students' mental models with pi elements

\begin{tabular}{|c|c|c|c|c|}
\hline Students & $\begin{array}{l}\text { Mental models of } \\
\text { wave-particle duality }\end{array}$ & $\begin{array}{l}\text { Comparison of knowledge } \\
\text { with peers (interview) }\end{array}$ & $\begin{array}{l}\text { Knowledge construction approach based } \\
\text { on peers' knowledge (questionnaire) }\end{array}$ & $\begin{array}{l}\text { Nature of peer discussion (peer } \\
\text { checklist) }\end{array}$ \\
\hline St1 & HM & $\begin{array}{l}\text { All of us know limited and } \\
\text { same level }\end{array}$ & $\begin{array}{l}\text { Asking questions and try to construct new } \\
\text { knowledge (with similar or conflicting } \\
\text { knowledge) }\end{array}$ & $\begin{array}{l}\text { Construction of new knowledge by } \\
\text { combining knowledge together }\end{array}$ \\
\hline St2 & WM & $\begin{array}{l}\text { All of us know limited and } \\
\text { same level }\end{array}$ & - & $\begin{array}{l}\text { Construction of new knowledge by } \\
\text { combining knowledge together }\end{array}$ \\
\hline St3 & QM & $\begin{array}{l}\text { My knowledge is more than } \\
\text { my peers' knowledge }\end{array}$ & $\begin{array}{l}\text { Asking questions and try to revise own } \\
\text { knowledge with the help of peer explanations } \\
\text { (with similar or conflicting knowledge) }\end{array}$ & $\begin{array}{l}\text { Construction of new knowledge by } \\
\text { revising originally different opinions }\end{array}$ \\
\hline \multirow[t]{2}{*}{ St4 } & QM & $\begin{array}{l}\text { All of us know well and } \\
\text { same level }\end{array}$ & $\begin{array}{l}\text { Directly accepting peer ideas (with similar } \\
\text { knowledge) }\end{array}$ & $\begin{array}{l}\text { Construction of new knowledge by } \\
\text { combining knowledge together }\end{array}$ \\
\hline & & & $\begin{array}{l}\text { Asking questions and try to construct new } \\
\text { knowledge (with conflicting knowledge) }\end{array}$ & \\
\hline St5 & $\mathrm{IM}$ & $\begin{array}{l}\text { All of us know limited and } \\
\text { same level }\end{array}$ & $\begin{array}{l}\text { Asking questions and try to construct new } \\
\text { knowledge (with similar or conflicting } \\
\text { knowledge) }\end{array}$ & Just discussion of already known \\
\hline St6 & $\mathrm{HM}$ & $\begin{array}{l}\text { My knowledge is less than } \\
\text { their knowledge }\end{array}$ & $\begin{array}{l}\text { Asking questions and revise own knowledge } \\
\text { with the new knowledge from peers (with } \\
\text { similar or conflicting knowledge) }\end{array}$ & Just discussion of already known \\
\hline
\end{tabular}

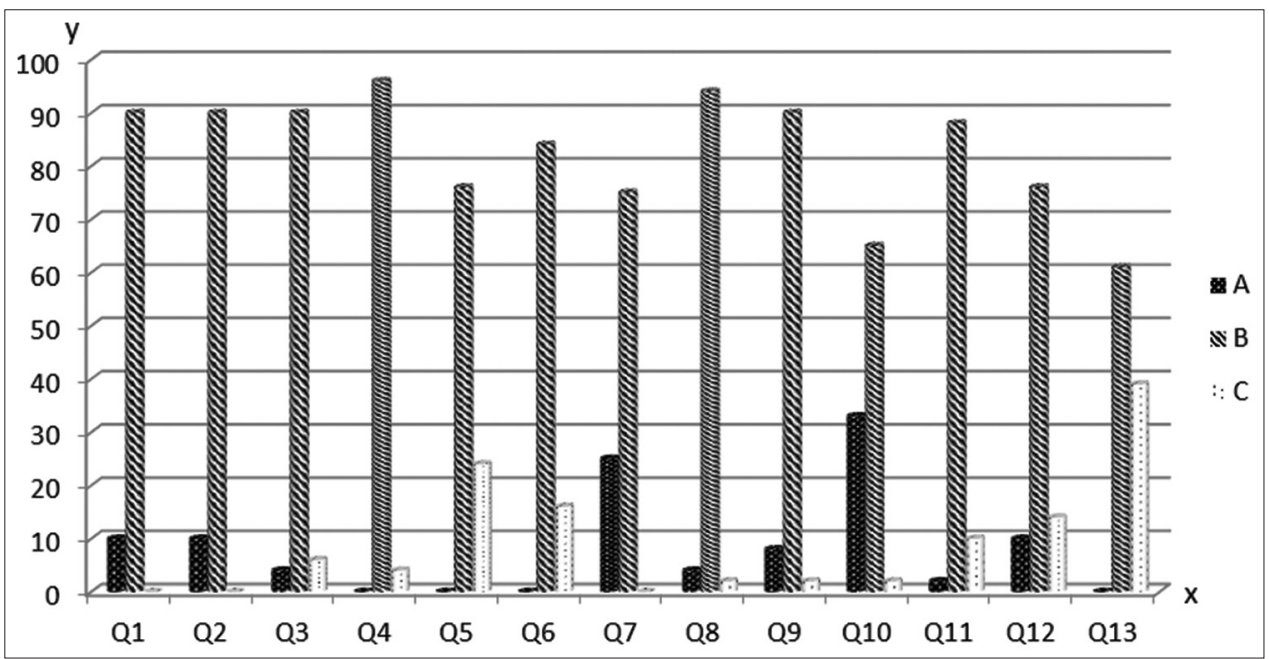

Figure 2: Students' approach to knowledge construction in the PI class (Choice A: directly accepting their peers' new ideas and memorizing them; Choice B: asking questions and revising their own knowledge with the new knowledge from their peers; and Choice C: being resistant to revise their knowledge). $x$ axis of the graph represents the questions and the $y$ axis represents the percentages of choices

St4: Having conflict definitely helped because either I would have to defend my own believes and the processes. It's like figure out if they are right or wrong. Or the other person would be more convincing I would realize that I was wrong or when they gave the right answer, I can realize that that was wrong... I think the conflict is definitely helpful for teaching... Maybe like what I said earlier just when you have disagreement, it can help to like solidify the knowledge in your head. It can also be helpful in being able to remember knowledge better...

This may be interpreted that the requirement of a radical conceptual change with the reconstruction of scientific knowledge for the concepts of quantum theory, which is a paradigm shift from the classical to the new perspective. In addition, Figure 3 presents how students in the class benefited from peer discussion in different ways.

Considering the percentages of other choices, the students taking the course thought mostly that peer discussion was helpful for recalling of their knowledge by their peers and reinforcing their knowledge (39\%). Another choice was getting feedback from their peers about their knowledge and improving their knowledge (35\%). The last one was having confliction between peers' knowledge and their knowledge and reconstructing their own knowledge (25\%). It could be concluded that all students thought peer discussion was helpful (since $0 \%$ saying not effective) in different ways and different from the traditional physics learning, PI may facilitate students' knowledge construction with 


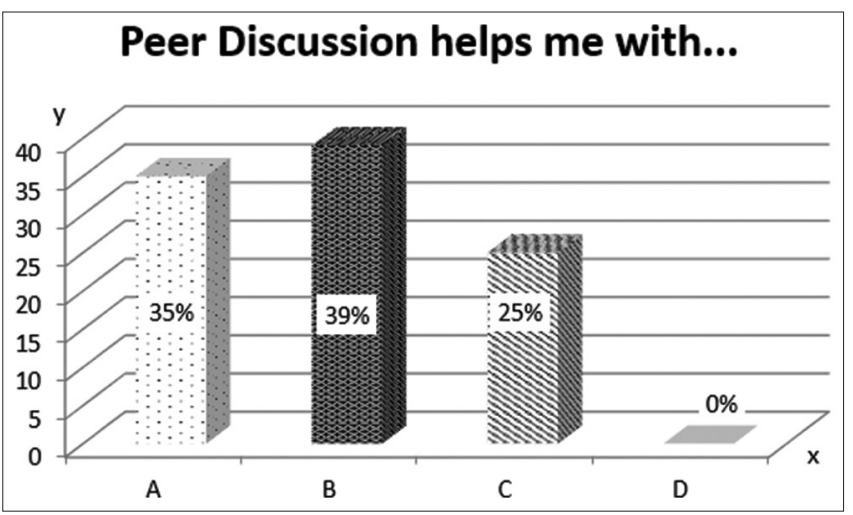

Figure 3: Distribution of students' ideas about the effectiveness of peer discussion. $x$ axis of the graph represents the questions and the $y$ axis represents the percentages of choices

instructional elements providing social interaction with peers.

\section{DISCUSSION, CONCLUSION, AND SUGGESTIONS}

This study was a case for the interaction of students' mental models with PI elements and it did not aim to generalize the findings. More specifically, it examined the interaction of mental models of wave-particle duality with the methodological issues and peers in PI classes in an undergraduate physics course. The following conclusions were drawn in this research:

Conclusion 1: Pre-class preparation may be explained as the methodological element of PI that students' mental models interacted with when students have the similar social environments for learning. The analyses of several data sources showed that groups' explanatory based annotations before classes were important for scientific understanding. In addition, explanation-like annotations given by students individually promoted scientific models. That is, when students have similar group environments (i.e. peers in the same group), then individual pre-class preparation facilitated the construction of scientific mental models of wave-particle duality. This may be because the topics were counter-intuitive that may allow new kind of unscientific thinking during classes unless students tried to make sense before classes.

Conclusion 2: Discussion of the other physical phenomena in peer discussion and not limiting the discussion with only the taught context may contribute to students' construction of scientific models. The analyses of several data sources also showed that some other group-related issues, such as good performance answering conceptual questions and discussion of additional concepts during classes, were important for scientific understanding. Peer discussion was another most important part of PI (Vickrey et al., 2015) because peers can explain the concepts more effectively (Mazur, 1997), and they can activate each other's appropriate cognitive resources (Wood et al., 2014). The peer discussion with questions could enhance the construction of scientific model "QM" because lecture periods were mainly used for the discussion and deepening students' understanding (Mazur, 1997). Quality of peer discussion is also important for students' models. Only contextual discussion of the questions without the inquiry of previous explanations during peer discussion might cause still keeping the classical ideas.

Conclusion 3: Confliction may be important for the construction of scientific knowledge. Students having scientific models mentioned the importance of confliction in the peer discussion while the students with unscientific models indicated the improvement of existing knowledge with the help of peers. This finding might suggest the requirement of a radical conceptual change with the reconstruction of new knowledge about wave-particle duality with confliction as the quantum theory is a paradigm shift from the classical to the new perspective.

Conclusion 4: The "physics thinking/knowledge of a peer" and "respect of a peer" may be two interrelated issues about peers in PI classes. PI provides students the opportunity to reveal their own ideas without memorizing the physics topics (Mazur, 1997) and based on students' persuading each other during discussion. Students in this research reported the importance of being kind and respectful during peer discussion because they commented that sometimes the knowledge of a peer could dominate peer discussion. As well as the importance of students' feelings or perceptions about their knowledge, the importance of peer knowledge was also observed in this research. Johnson-Laird (2004) revealed the importance of background knowledge on the construction of mental models.

Conclusion 5: Satisfaction about knowledge may have a role on the scientific mental models. The students feeling satisfaction about their knowledge presented scientific mental models, however the others explaining having limited knowledge presented unscientific models. Students' awareness and satisfaction of their knowledge during class might facilitate how they organized scientific knowledge about quantum physics (Didiş Körhasan et al., 2018).

Conclusion 6: Most of students taking this PI course had a tendency to construct their knowledge and all of them benefited from peer discussion in different ways. This showed that students tried to organize their knowledge as well as they answered the questions with their peers. In addition, student explained that they all benefited from peer discussions in different ways such as by remembering and reinforcing their knowledge, by getting feedback and by reconstructing their knowledge. These findings might also be interpreted that instructional elements providing social interaction with peers may have positive influence on peer discussion, and this may facilitate knowledge construction and organization in a peerinteracted learning environment.

Because scientific knowledge required the inquiry and discussion of existing knowledge, PI allowed these students to discuss the contradictive concepts, to realize the scientific 
knowledge, and to construct their mental models with peer discussion. Hence, different from the existing studies investigating students' mental models of quantum physics in lecture-based teaching environments, this study discussed students' mental models in a PI course and how they interacted with the issues emerging from the PI environment. The findings of this mixed methods research point out the benefits of this approach for students' learning the upper-level physics concepts. For facilitation of construction of scientific mental models, the findings suggest promoting students' (1) pre-class preparation as an instructional element, and (2) discussion of additional concepts and conflicting ideas in peer groups during PI.

\section{ACKNOWLEDGMENT}

The author thanks The Scientific and Technological Research Council of Turkey (TÜBITAK), Turkish Academy of Sciences (TÜBA-GEBİP/2017), Zonguldak Bülent Ecevit University, Harvard University, Prof. Dr. Eric Mazur and Dr. Kelly Miller for their precious support and feedback.

\section{REFERENCES}

Ayene, M., Krick, J., Damtie, B., Ingerman, A., and Thacker, B. (2019). A holistic picture of physics student conceptions of energy quantization, the photon concept, and light quanta interference. International Journal of Science and Mathematics Education, 17, 1049-1070.

Collins, A., and Gentner, D. (1987). How people construct mental models. In: Holland, D., and Quinn, N. (Eds.), Cultural Models in Language and Thought. United Kingdom: Cambridge University Press. pp. 243-265.

Crouch, C.H., and Mazur, E. (2001). Peer instruction: Ten years of experience and results. American Journal of Physics, 69(9), 970-977.

Didiş Körhasan, N., and Miller, K. (2020). Students' mental models of waveparticle duality. Canadian Journal of Physics, 98(3), 266-273.

Didiş Körhasan, N., and Wang, L. (2016). Students' mental models of atomic spectra. Chemistry Education: Research and Practice, 17, 743-755.

Didiş Körhasan, N., Eryılmaz, A., and Erkoç, Ş. (2016). The influence of instructional interactions on students' mental models about the quantization of physical observables: A modern physics course case. European Journal of Physics, 37, 1-29.

Didiş Körhasan, N., Eryılmaz, A., and Erkoç, Ş. (2018). The role of metacognition in students' mental models of the quantization. Science Education International, 29(3), 183-191.

Didiş, N., Eryılmaz, A., and Erkoç, Ş. (2014). Investigating students' mental models about the quantization of light, energy and angular momentum. Physical Review Special Topics: Physics Education Research, 10(2), $1-28$.

Fagen, A.P., Crouch, C.H., and Mazur, E. (2002). Peer instruction: Results from a range of classrooms. The Physics Teacher, 40(4), 206-209.

Fraenkel, J.R., and Wallen, N.E. (2000). How to Design and Evaluate Research in Education. United Kingdom: McGraw Hill.

Giuliodori, M.J., Lujan, H.L., and DiCarlo, S.E. (2006). Peer instruction enhanced student performance on qualitative problem-solving questions. Advances in Physiology Education, 30(4), 168-173.

Gök, T. (2012). The impact of peer instruction on college students' beliefs about physics and conceptual understanding of electricity and magnetism. International Journal of Science and Mathematics Education, 10, 417-436.
Gök, T. (2015). An investigation of students' performance after peer instruction with stepwise problem-solving strategies. International Journal of Science and Mathematics Education, 13, 561-582.

Hewson, P.W. (1981). A conceptual change approach to learning science. European Journal of Science Education, 3, 383-396.

Hewson, P.W. (1984). The role of conceptual conflict in conceptual change and the design of science instruction. Instructional Science, 13(1), 1-13.

Jeong, H., and Chi, M.T.H. (2007). Knowledge convergence and collaborative learning. Instructional Science, 35(4), 287-315.

Johnson-Laird, P.N. (2004). The history of mental models. In: Manktelow, K., and Chung, M.C. (Eds.), Psychology of Reasoning: Theoretical And Historical Perspectives. United Kingdom: Psychology Press. pp. 179212.

Ke, J.L., Monk, M., and Duschl, R. (2005). Learning introductory quantum mechanics. International Journal of Science Education, 27(13), 15711594.

Lasry, N., Mazur, E., and Watkins, J. (2008). Peer instruction: From Harvard to community colleges. American Journal of Physics, 76, 1066-1069.

Lorenzo, M., Crouch, C.H., and Mazur, E. (2006). Reducing the gender gap in the physics classroom. American Journal of Physics, 74(2), 118-122.

Mazur, E. (1997). Peer Instruction: A User's Manual. New Jersey, United States: Pearson and Prentice Hall.

Miller, K., Lasry, N., Lukoff, B., Schell, J., and Mazur, E. (2014). Conceptual question response times in peer instruction classrooms. Physical Review Special Topics: Physics Education Research, 10(2), 020113.

Miller, K., Schell, J., Ho, A., Lukoff, B., and Mazur, E. (2015). Response switching and self-efficacy in peer instruction classrooms. Physical Review Special Topics: Physics Education Research, 11, 010104.

Miller, K., Zyto, S., Karger, D., Yoo, J., and Mazur, E. (2016). Analysis of student engagement in an online annotation system in the context of a flipped introductory physics class. Physical Review Special Topics: Physics Education Research, 12, 020143.

Norman, D. (1983). Some observations on mental models. In: Gentner, D., and Stevens, A. (Eds.), Mental Models. New Jersey: Lawrence Erlbaum Associates. pp. 7-14.

Park, E.J., and Light, G. (2009). Identifying atomic structure as a threshold concept: Student mental models and troublesomeness. International Journal of Science Education, 31(2), 233-258.

Posner, G.J., Strike, K.A., Hewson, P.W., and Gertzog, W.A. (1982). Accommodation of a scientific conception: Toward a theory of conceptual change. Science Education, 66, 211-227.

Singh, C. (2005). Impact of peer interaction on conceptual test performance. American Journal of Physics, 73(5), 446-451.

Smith, M.K., Wood, W.B., Adams, W.K., Wieman, C., Knight, J.K., Guild, N., and Su, T.T. (2009). Why peer discussion improves student performance on in-class concept questions. Science, 323, 122-124.

Stefani, C., and Tsaparlis, G. (2009). Students' levels of explanations, models, and misconceptions in basic quantum chemistry: A phenomenographic study. Journal of Research in Science Teaching, 46(5), 520-536.

van der Veer, G.C., Kok, E., and Bajo, T. (1999). Conceptualising mental representations of mechanics: A method to investigate representational change. In: Kayser, D., and Vosniadou, S. (Eds.), Modelling Changes in Understanding: Case Studies in Physical Reasoning. Amsterdam, Netherlands: Elsevier Science. pp. 44-60.

Vickrey, T., Rosploch, K., Rahmanian, R., Pilarz, M., and Stains, M. (2015). Research-based implementation of Peer Instruction: A literature review. CBE-Life Science Education, 14, 1-11.

Vygotsky, L. (1978). Mind in Society. Massachusetts, United States: Harvard University Press.

Wood, A.K., Galloway, R.K., Hardy, J., and Sinclair, C.M. (2014). Analyzing learning during Peer Instruction dialogues: A resource activation framework. Physical Review Special Topics: Physics Education Research, 10, 020107. 


\section{Peer Checklist}

\section{APPENDIX}

During the second round of questions, select up to three statements from below that best describe your interaction with peer(s) during discussion:

- I answer the questions by myself without discussion

- We usually all had the same answer in the first round so there was no discussion

- We discussed what we had already known and arrived at the same conclusion

- We constructed new knowledge by combining our knowledge together

- We did not know how to approach the questions, so we usually just guessed

- We had different opinions and we kept our own ideas during discussion

- We were confused because we had different opinions

- We constructed new knowledge by revising our originally different opinions 